\title{
EDUCAÇÃO AMBIENTAL COM ABORDAGEM CTS/CTSA NA EDUCAÇÃO DE JOVENS E ADULTOS: UM CAMINHO PARA O EXERCÍCIO DA CIDADANIA.
}

\author{
JÉSSICA ENDRINGER DIAS GAVA \\ IFES campus Vila Velha \\ jessicaend@hotmail.com \\ JOCILENE GADIOLI DE OLIVEIRA \\ UNIDOCTUM - SEDU/ES \\ jocilenegadioli@gmail.com
}

\section{RESUMO:}

A Educação de Jovens e Adultos é destinada às pessoas que por motivos variados não concluíram seus estudos no tempo adequado, que podem ter dificuldades na compreensão de termos como sustentabilidade e reciclagem. O presente trabalho tem o propósito de identificar e analisar práticas de educação ambiental com enfoque na abordagem CTSA (Ciência, Tecnologia, Sociedade e Ambiente) voltadas para a EJA. A pesquisa é de natureza qualitativa, por utilizar a pesquisa bibliográfica e documental, para a coleta de dados, que se fundamenta em guiar o conhecimento científico para que contribua para a vida do aluno no geral e principalmente possibilite uma visão mais crítica e consciente de mundo, bem como práticas simples e efetivas de reaproveitamento de óleos, formas para evitar a poluição, contribuem para o aumento da qualidade de vida, tudo isso com interatividade na criação de ferramentas virtuais, como a utilização do Blog escolar.

\section{PALAVRAS-CHAVE:}

EDUCAÇÃO AMBIENTAL; EJA; CTSA.

\begin{abstract}
:
Youth and Adult Education is for people with varied motives who have not completed their studies without adequate time, who may have difficulties in understanding terms such as sustainability and recycling. This paper aims to identify and analyze environmental education practices focusing on the STSE (Science, Technology, Society and Environment) approach focused on YAE. The research is qualitative in nature, as it uses the bibliographic and documentary research to collect data, which is based on guiding scientific knowledge, so that it contributes to the student's life in general and especially enables a more critical and conscious view, as well as simple and effective oil reuse practices, ways to avoid pollution, increased quality of life, all with interactivity in the creation of virtual tools, such as the use of the School Blog.
\end{abstract}

\section{KEYWORDS:}

\section{(1) (3)}




\section{INTRODUÇÃO}

O tema de pesquisa trabalhado é o ensino de Ciência, Tecnologia, Sociedade e Ambiente - CTSA na EJA, com o objetivo de identificar e analisar práticas de Educação Ambiental, que melhorem a qualidade de vida por meio de práticas sustentáveis.

Segundo a Lei de Diretrizes e Bases 9.394 (BRASIL, 1996) a Educação de Jovens e Adultos - EJA é assegurada para todos os alunos que não tiveram acesso, ou não concluíram seus estudos da Educação Básica na idade própria, a matrícula na EJA deve ser efetuada no Ensino Fundamental para alunos maiores de 15 anos e, alunos com 18 anos completos ao Ensino Médio, de acordo com o aproveitamento de estudos de cada estudante.

Para Moura (2006), os alunos da EJA são heterogêneos, tanto pelo fator idade, como pelas visões de mundo que trazem consigo. Nesse grupo encontram-se estudantes que devem ser reintegrados a sociedade e ao ensino, suas experiências de vida devem ser valorizadas pelo professor.

A abordagem CTSA na EJA é importante para reflexão das situações problemas que envolvem as Ciências e as tecnologias no contexto social, conhecendo conceitos e contribuindo para a sustentabilidade, constituindo assim pensamentos e posicionamentos para as produções científicas. (SANTOS, QUINATO, OLIVEIRA, 2011).

A pesquisa partiu do problema que em sala de aula os alunos não conhecem ou não entendem a proporção das ações antropológicas no futuro da biodiversidade do planeta Terra e da hipótese que as escolas ainda possuem dificuldades em entender a Educação Ambiental como um tema que pode ser trabalhado inter/transdisciplinar 
por meio de conceitos e ações que minimizam os efeitos nocivos do homem no meio ambiente.

Além disso, percebeu-se a necessidade de trabalhar a temática de forma lúdica, por meio da confecção de jornais ou blogs de ciências elaborados pelos próprios estudantes, bem como a utilização de outros recursos, como: a utilização de vídeos, jogos, que buscam incentivar nos alunos a criação de atitudes concretas para a melhoria do meio em que vivemos, como fabricação de sabão de óleos, reutilizando assim um material que ia ser descartado e poluiria corpos de água e o solo, reciclagem do lixo doméstico, entre outras atitudes que contribuem para a sustentabilidade.

Com isso, partiu-se do pressuposto que a tomada de consciência por meio de práticas pedagógicas, que estimulam os professores a trabalharem em suas escolas a alfabetização científica voltada à Educação Ambiental de forma integrada às outras disciplinas, para assim formarmos cidadãos aptos a transformar a realidade social e ambiental do seu próprio entorno. Assim, o objetivo central de pesquisa é o de identificar e analisar práticas de educação ambiental com enfoque na abordagem CTSA voltadas para a Educação de Jovens e Adultos. Para conseguir atingir esse objetivo, o estudo proposto procurou aprofundar o estudo sobre sustentabilidade e consumo sustentável, contribuindo para o conhecimento científico do público-alvo da EJA, além de verificar possibilidades e limites de uma educação científica voltada à prática da cidadania e por meio de práticas sustentáveis.

A principal justificativa para o trabalho com o tema Educação Ambiental é a contribuição para a formação de cidadãos conscientes, voltada para a conservação dos recursos naturais, priorizando o bem-estar socioambiental. Para isso foi necessário abordar a temática nas escolas de forma interdisciplinar e crítica, para que 
os alunos obtenham mais que informações e conceitos, a partir disso formem valores para haver mudanças de atitudes e alcançar o equilíbrio entre as ações do homem e natureza.

A Educação de Jovens e Adultos faz parte da Educação Básica, norteada pelos parâmetros Curriculares Nacionais - PCN, assim como qualquer modalidade de ensino, a EJA inclui como tema a Educação Ambiental, que deverá ser abordada de maneira transversal. É necessário que todas as disciplinas trabalhem o tema. Os alunos da EJA são trabalhadores que buscam se reengajarem na sociedade, a fim de melhorar suas oportunidades de vida, alunos esses que não obtiveram sucessos no ensino regular. Muitas vezes o professor encontra-se com o desinteresse desses alunos para a aprendizagem, que refletem em um baixo rendimento, dificuldades para compreensão dos conceitos e conteúdos. Portanto, é necessário que o professor leve em consideração o saber prévio dos alunos, integre o conceito científico e as experiências trazidas pelos estudantes (FREITAS, SANTOS e BARRETO, 2009).

A Base Nacional Comum Curricular (BNCC de 2018) destaca a Educação Ambiental como um tema transversal, ou seja, obrigatório a todas as disciplinas em um contexto interdisciplinar, além de acatar as leis referentes ao tema em questão. A BNCC visa entrelaçar os conteúdos mais variados, aos impactos gerados pelo homem ao ambiente, formas de preservação dos recursos naturais e sustentabilidade (BRASIL, 2018).

\section{METODOLOGIA}

A pesquisa apresentada foi realizada no CEEJA de Linhares-ES, onde há uma carência de trabalhos voltados para o meio ambiente. A escola possui uma estrutura diferenciada das demais, com o ensino organizado através de módulos, a Educação 
Ambiental ainda é restrita às disciplinas específicas e contemplada dentro dos módulos dessas disciplinas. O ensino no CEEJA é semipresencial, o aluno leva o módulo a ser estudado para casa e só retorna à escola para sanar suas dúvidas e realizar a avaliação, isso inviabiliza a execução projetos na escola, a sequência didática então não é uma opção que funcione no Ensino Fundamental II e Ensino Médio, mas no Ensino Fundamental I que contempla turmas de alfabetização e básico, pois os alunos possuem uma regularidade maior e são ensinados em turmas, diferente das séries finais que são atendidos pelos professores individualmente.

Quanto ao público-alvo, sua maioria está buscando a inclusão social, que, por algum motivo, deixou de estudar e busca o ingresso no mercado de trabalho. Esses alunos apresentam nítidas dificuldades de aprendizagens das mais variadas, entre elas a compreensão dos termos sustentabilidade e reciclagem.

A Educação de Jovens e Adultos é contemplada com alunos acima de 15 anos em distorção série/idade. Os participantes da pesquisa foram os alunos da alfabetização dos turnos matutino e vespertino. Os alunos do turno matutino participaram da sequência didática (S.D.) sobre alimentação saudável, na qual foi elaborada e acompanhada pelo próprio pesquisador e aplicada pela professora regente, para um quantitativo de 14 alunos. Já a S.D. sobre poluição do solo foi aplicada no turno vespertino para 12 alunos pela professora regente, também para uma turma de alfabetização, da mesma forma que a SD anterior, as duas sequências didáticas foram aplicadas em forma de rodas de conversa, ambas as turmas de alfabetização que tiveram a opção de participar.

As Sequências Didáticas foram embasadas no modelo de Delizoicov et. al. (2002) respeitando os três momentos pedagógicos (3MP): Problematização, Organização do Conhecimento e Aplicação do Conhecimento. A problematização leva 
em consideração a vivência cotidiana dos estudantes e permite que o professor conheça um pouco do que seus alunos pensam sobre o tema, a organização do conhecimento o professor media o conhecimento e permite a união do conhecimento-prévio e o conhecimento científico, por último a aplicação do conhecimento permite que o aluno demonstre o conhecimento adquirido. (MUENCHEN; DELIZOICOV, 2014).

Trata-se de um pesquisa de natureza qualitativa, com procedimentos da pesquisa bibliográfica e documental, para a coleta de dados, com o objetivo de buscar por práticas de Educação Ambiental que possam fundamentar a proposta de que as escolas precisam trabalhar a Educação Ambiental como um tema transversal e não como obrigação das disciplinas de Ciências e Biologia, como acontece na maioria delas, com vistas a compartilhar conceitos e ações que possam favorecer uma compreensão mais integral da relação do ser humano com o ambiente.

Após as sequências didáticas serem aplicadas para as turmas de alfabetização, foram distribuídas pelas salas de atendimentos de todas as disciplinas do CEEJA de Linhares-ES convites aos alunos do Ensino Fundamental II e Médio, entretanto, apenas 4 alunos se interessaram e realizaram as pesquisas com o contexto do meio ambiente, que tinha por sugestão os temas: poluição do solo, água, conservação, tudo que envolvesse o meio ambiente, contamos com o auxílio dos professores correspondentes das disciplinas cursadas. Só participaram da pesquisa os alunos que se dispuseram, não houve atribuição de notas e avaliações, devido à portaria de abril de 2018 publicada no Diário oficial do ES, que regulamenta que os alunos dos CEEJAs e NEEJAs do Estado sejam avaliados somente por avaliações com valor de 100 pontos. Os alunos que optaram por não participar do presente projeto continuaram 
desenvolvendo as atividades propostas pela metodologia da disciplina em que estão matriculados.

A partir do resultado dessa pesquisa realizada pelos alunos e a culminância das sequências didáticas foi feito um Blog escolar, que os demais estudantes puderam/podem acessar e interagir online.

As análises e as interpretações que foram efetuadas a partir dos dados coletados guiaram a produção do conhecimento e o entendimento de que podemos ter uma educação científica que prime pela construção de um ambiente justo e sustentável.

\section{RESULTADOS E DISCUSSÕES}

As práticas pesquisadas de Educação Ambiental com enfoque na abordagem CTSA originou a organização e a realização das sequências didáticas conforme constam dos Quadros 1 e 2, levando em consideração o modelo de Delizoicov et. al. (2002).

Quadro 1. Sequência Didática- Alfabetização. Fonte: Arquivo pessoal da autora, 2018.

\begin{tabular}{|l|l|}
\hline Sequência Didática (SD) \\
\hline Autores: & Jéssica Endringer Dias Gava e Maria Rosa Sibien \\
\hline Título: & $\begin{array}{l}\text { Poluição do solo: óleos domésticos, descarte inadequado e seus efeitos } \\
\text { no Meio Ambiente. }\end{array}$ \\
\hline Público Alvo: & Ensino Fundamental 1. Alfabetização do CEEJA de Linhares. \\
\hline Problematização: & $\begin{array}{l}\text { Em Linhares-ES principalmente no centro, local das instalações do CEEJA, } \\
\text { podemos observar hábitos de descarte do lixo doméstico nas vias públicas, } \\
\text { ocasionando danos ao meio ambiente, à saúde da população, além da } \\
\text { poluição de corpos de água com o descarte incorreto de resíduos, } \\
\text { principalmente os óleos domésticos, causando contaminaçãodo solo, da } \\
\text { água, dentre outros. }\end{array}$ \\
\hline Objetivo Geral: & $\begin{array}{l}\text { Sensibilizar os alunos para uma visão crítica e reflexiva sobre noções de } \\
\text { proteção ao meio ambiente, usando a reciclagem/ reaproveitamento } \\
\text { como uma alternativa no processo de minimizar a quantidade de lixo, para } \\
\text { que o planeta torne-se mais sustentável e capaz de atender as } \\
\text { necessidades de gerações futuras. }\end{array}$ \\
\hline
\end{tabular}


Conteúdos e Métodos

\begin{tabular}{|c|c|c|c|}
\hline Aula & Objetivos Específicos & Conteúdos & Dinâmicas \\
\hline 01 & $\begin{array}{l}\text { Identificar } \\
\text { conhecimento dos alunos } \\
\text { sobre Resíduos sólidos. }\end{array}$ & $\begin{array}{l}\text { Resíduos sólidos; } \\
\text { O que é lixo? } \\
\text { Como descartar o } \\
\text { lixo? }\end{array}$ & Rodas de conversa \\
\hline \multicolumn{4}{|c|}{ Conteúdos e Métodos } \\
\hline Aula & Objetivos Específicos & Conteúdos & Dinâmicas \\
\hline 02 & $\begin{array}{l}\text { Compreender o quanto a } \\
\text { poluição doméstica afeta } \\
\text { o meio ambiente; } \\
\text { Construir um olhar crítico } \\
\text { sobre a poluição } \\
\text { ambiental. }\end{array}$ & $\begin{array}{l}\text { Resíduos sólidos; } \\
\text { O que é lixo? } \\
\text { Como descartaro } \\
\text { lixo? } \\
\text { Reciclagem; } \\
\text { Reaproveitamento; } \\
\text { Poluição causada pelos } \\
\text { resíduos sólidos, óleos } \\
\text { usados. }\end{array}$ & $\begin{array}{l}\text { Aula expositiva, } \\
\text { leitura e discussão da } \\
\text { matéria do Jornal } \\
\text { escolar. }\end{array}$ \\
\hline \multicolumn{4}{|c|}{ Conteúdos e Métodos } \\
\hline Aula & Objetivos Específicos & Conteúdos & Dinâmicas \\
\hline 03 & $\begin{array}{l}\text { Compreender que o } \\
\text { homem é parte do } \\
\text { ambiente em que } \\
\text { vive e que suas ações têm } \\
\text { consequência para o meio. }\end{array}$ & $\begin{array}{l}\text { Resíduos sólidos; } \\
\text { O que é lixo? } \\
\text { Como descartar o lixo? } \\
\text { Reciclagem; } \\
\text { Reaproveitamento; } \\
\text { Poluição causada pelos } \\
\text { resíduos sólidos e óleos } \\
\text { usados. }\end{array}$ & $\begin{array}{l}\text { Atividades sobre } 0 \\
\text { tema proposto. }\end{array}$ \\
\hline \multicolumn{2}{|l|}{ Avaliação: } & \multicolumn{2}{|c|}{$\begin{array}{l}\text { Confecção do sabão de álcool com óleos } \\
\text { usados, que os próprios alunos trouxeram e } \\
\text { executaram para apontar como forma de } \\
\text { prevenção da poluição do solo e corpos de } \\
\text { água pelo descarte inadequado desses óleos } \\
\text { usados. Toda confecção foi realizada pelos } \\
\text { alunos. }\end{array}$} \\
\hline Referencial & Bibliográfico: & \multicolumn{2}{|c|}{$\begin{array}{l}\text { FREIRE, P. Conscientização: teoria e prática da } \\
\text { libertação uma introdução ao pensamento de } \\
\text { Paulo Freire. São Paulo,1980. }\end{array}$} \\
\hline \multicolumn{2}{|c|}{ Bibliografia consultada: } & \multicolumn{2}{|c|}{$\begin{array}{l}\text { DELIZOICOV, Demétrio; MUENCHEN, Cristiane. } \\
\text { Os Três Momentos Pedagógicos na Edição de } \\
\text { Livros para Professores. Ensino de Ciências e } \\
\text { Tecnologia em Revista,Vol.1, } 2011 \text {. } \\
\text { OLIVEIRA, E.M. Educação ambiental uma } \\
\text { possível abordagem. } 2 \text { ed. } 2000 .\end{array}$} \\
\hline
\end{tabular}


Quadro 2. Sequência Didática- Alfabetização. Fonte: Arquivo pessoal da autora, 2018.

\begin{tabular}{|c|c|c|c|c|}
\hline \multicolumn{5}{|c|}{ Sequência Didática (SD) } \\
\hline Autores: & \multicolumn{4}{|c|}{ Jéssica Endringer Dias Gava e Valéria dos Santos } \\
\hline Título: & \multicolumn{4}{|c|}{ Alimentação saudável e o Meio Ambiente. } \\
\hline Público Alvo: & \multicolumn{4}{|c|}{ Ensino Fundamental 1. Alfabetização do CEEJA de Linhares. } \\
\hline Problematização: & \multicolumn{4}{|c|}{$\begin{array}{l}\text { A indústria alimentícia causa muitos impactos no Meio Ambiente, quanto } \\
\text { mais industrializada a alimentação é, mais embalagens e resíduos no } \\
\text { Meio Ambiente. }\end{array}$} \\
\hline Objetivo Geral: & \multicolumn{4}{|c|}{$\begin{array}{l}\text { Incentivar os alunos para uma visão crítica e reflexiva sobre noções de } \\
\text { proteção ao meio ambiente, com enfoque na alimentação saudável como } \\
\text { forma de redução dos resíduos sólidos no Meio Ambiente. }\end{array}$} \\
\hline \multicolumn{5}{|c|}{ Conteúdos e Métodos } \\
\hline Aula & \begin{tabular}{|l|} 
Objetivos \\
Específicos
\end{tabular} & \multicolumn{2}{|l|}{ Conteúdos } & Dinâmicas \\
\hline 01 & $\begin{array}{l}\text { Identificar o } \\
\text { conhecimento } \\
\text { dos alunos } \\
\text { sobre } \\
\text { alimentação } \\
\text { saudável. }\end{array}$ & \multicolumn{2}{|l|}{$\begin{array}{l}\text { Alimentação saudável; } \\
\text { Como a alimentação pode } \\
\text { influenciar na degradação do } \\
\text { Meio Ambiente? }\end{array}$} & Rodas de conversa. \\
\hline \multicolumn{5}{|c|}{ Conteúdos e Métodos } \\
\hline Aula & $\begin{array}{l}\text { Objetivos } \\
\text { Especificos }\end{array}$ & \multicolumn{2}{|l|}{ Conteúdos } & Dinâmicas \\
\hline 02 & \begin{tabular}{|lr} 
Compreender & O \\
quanto & a \\
alimentação & \\
humana & \\
desregrada & \\
afetar & o \\
equilíbrio do \\
meio ambiente; \\
Construir um \\
olhar crítico \\
sobre r a \\
alimentação.
\end{tabular} & \multicolumn{2}{|l|}{$\begin{array}{l}\text { Importância da alimentação } \\
\text { saudável para a saúde; } \\
\text { Alimentação industrial e seus } \\
\text { impactos no meio ambiente; } \\
\text { Consumor consciente, } \\
\text { alimentação saudável e } \\
\text { benefícios ao Meio Ambiente. }\end{array}$} & $\begin{array}{l}\text { Aula expositiva, leitura } \\
\text { e discussão da matéria } \\
\text { do Jornal escolar. }\end{array}$ \\
\hline \multicolumn{5}{|c|}{ Conteúdos e Métodos } \\
\hline Aula & \begin{tabular}{|l|} 
Objetivos \\
Específicos
\end{tabular} & Conteúdos & \multicolumn{2}{|c|}{ Dinâmicas } \\
\hline 03 & $\begin{array}{l}\text { Compreender } \\
\text { que o homem é } \\
\text { parte do } \\
\text { ambiente em } \\
\text { que vive e que } \\
\text { suas ações têm }\end{array}$ & \begin{tabular}{|l|} 
Frutas e verduras; \\
Produtos orgânicos; \\
Receita da salada de \\
Frutas.
\end{tabular} & & $\begin{array}{l}\text { ta de Compras; Ditado; } \\
\text { vidades sobre } \\
\text { antidades. }\end{array}$ \\
\hline
\end{tabular}


Rev. Elet. DECT, Vitória - Espírito Santo, v. 10, n. 1, p.148-172, setembro de 2020

\begin{tabular}{|c|c|c|}
\hline $\begin{array}{l}\text { conse } \\
\text { para }\end{array}$ & $\begin{array}{c}\text { quências } \\
\text { o meio. }\end{array}$ & \\
\hline \multicolumn{2}{|l|}{ Avaliação: } & $\begin{array}{l}\text { Cada aluno é responsável por levar uma } \\
\text { fruta, como previamente combinado. } \\
\text { Confraternização da salada de frutas. }\end{array}$ \\
\hline \multicolumn{2}{|l|}{ Referencial Bibliográfico: } & 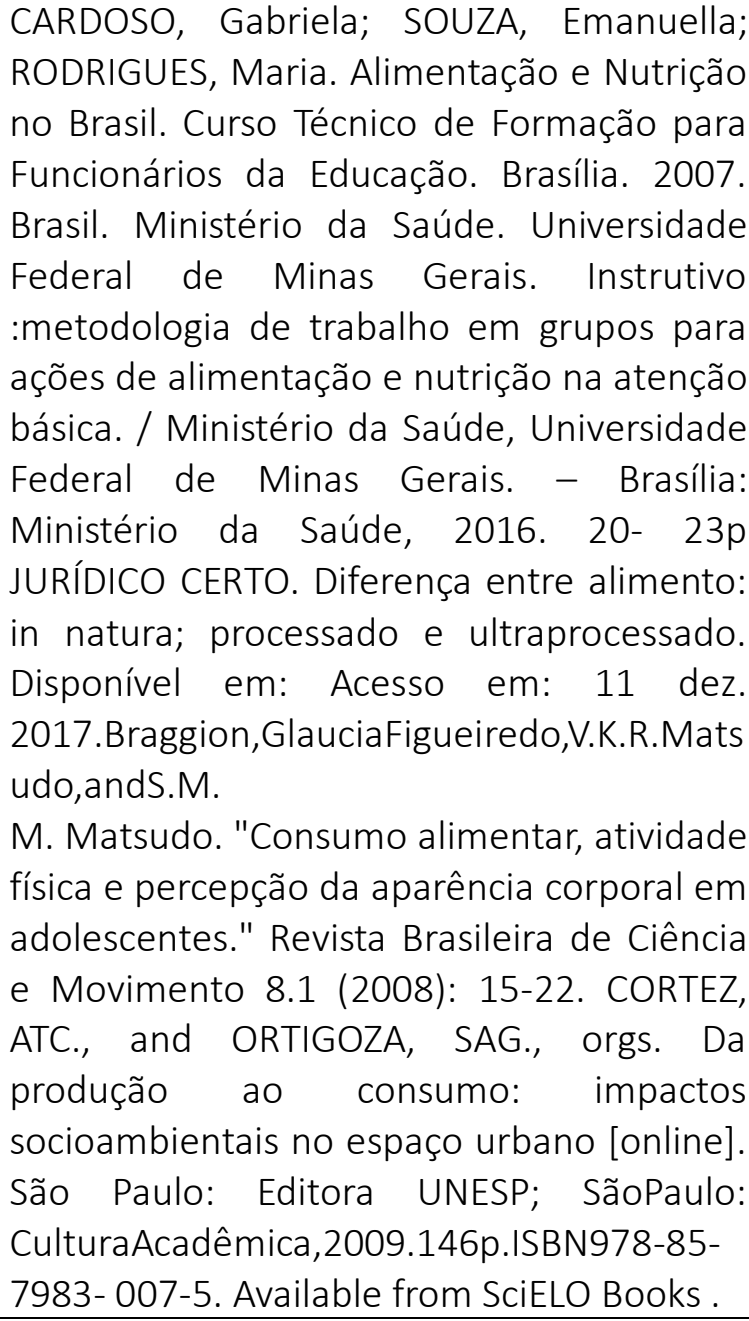 \\
\hline Bibliografia consultada: & & $\begin{array}{l}\text { Alimentação saudável. Depto de Nutrição } \\
\text { da Faculdade de Ciências da Saúde da } \\
\text { Universidade de Brasília (FS/ UnB). Acesso } \\
\text { em: } 08 \text { de dezembro de } 2017 \text {. } \\
\text { Hoffman, R. Agricultura familiar e consumo } \\
\text { de alimentos. Rev. Segurança Alimentar e } \\
\text { Nutricional, Campinas - SP, Brasil v.21, n.1 } \\
\text { (2014) } \\
\text { Ministério da Educação. Alimentação e } \\
\text { nutrição no Brasil. Disponível em: } \\
<\text { http://portal.mec.gov.br/index.php?opti } \\
\text { Acesso em: } 08 \text { de dezembro de } 2017 \text {. }\end{array}$ \\
\hline
\end{tabular}


As sequências didáticas apresentadas e que foram trabalhadas com a turma de alfabetização do CEEJA de Linhares-ES, contou com o auxílio das professoras regentes e foi desenvolvido de forma enriquecedora, pois os estudantes participaram ativamente das rodas de conversa, compartilhando seus conhecimentos-prévios sobre o tema e muitos já possuíam o hábito de fabricarem sabão de álcool em barra, líquido ou em pasta em suas casas, já reaproveitando óleos usados, bem como reaproveitando recipientes para condicionar esse sabão. Tanto que eles mesmos quiseram fabricar o sabão, conforme a figura 1.

Figura 1- Alunos da turma de Alfabetização do CEEJA de Linhares do turno vespertino, fazendo sabão de álcool com reaproveitamento de óleos usados. Fonte: Arquivo pessoal da autora, 2018.

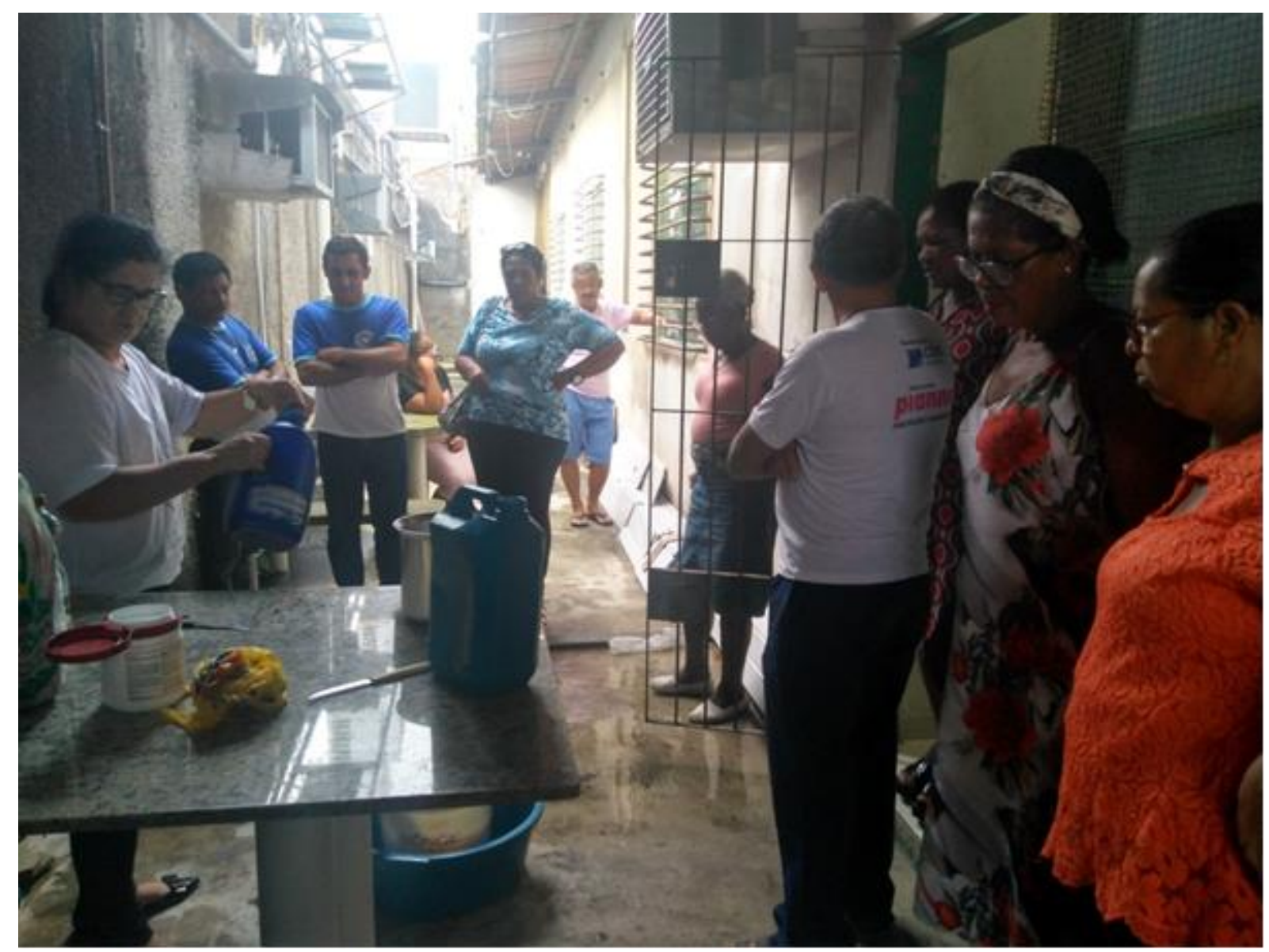

Já a turma de alfabetização do turno matutino, ficaram mais surpresos com o tema da sequência didática, em sua maioria não haviam parado para pensar que uma 
alimentação com produtos industrializados afetasse tanto a natureza, que uma alimentação saudável além de ser benéfica para a saúde contribui também para a redução na produção de lixo, tanto que conforme a figura 2 na distribuição da salada de frutas confeccionada e com alimentos trazidos por eles de casa, ainda foi feita com copos descartáveis, mas todos assumiram o compromisso de substituírem os utensílios descartáveis por reutilizáveis.

Figura 2: Alunos da turma de Alfabetização do CEEJA de Linhares do turno matutino, compartilhando a salada de frutas. Fonte: Arquivo pessoal da autora, 2018.

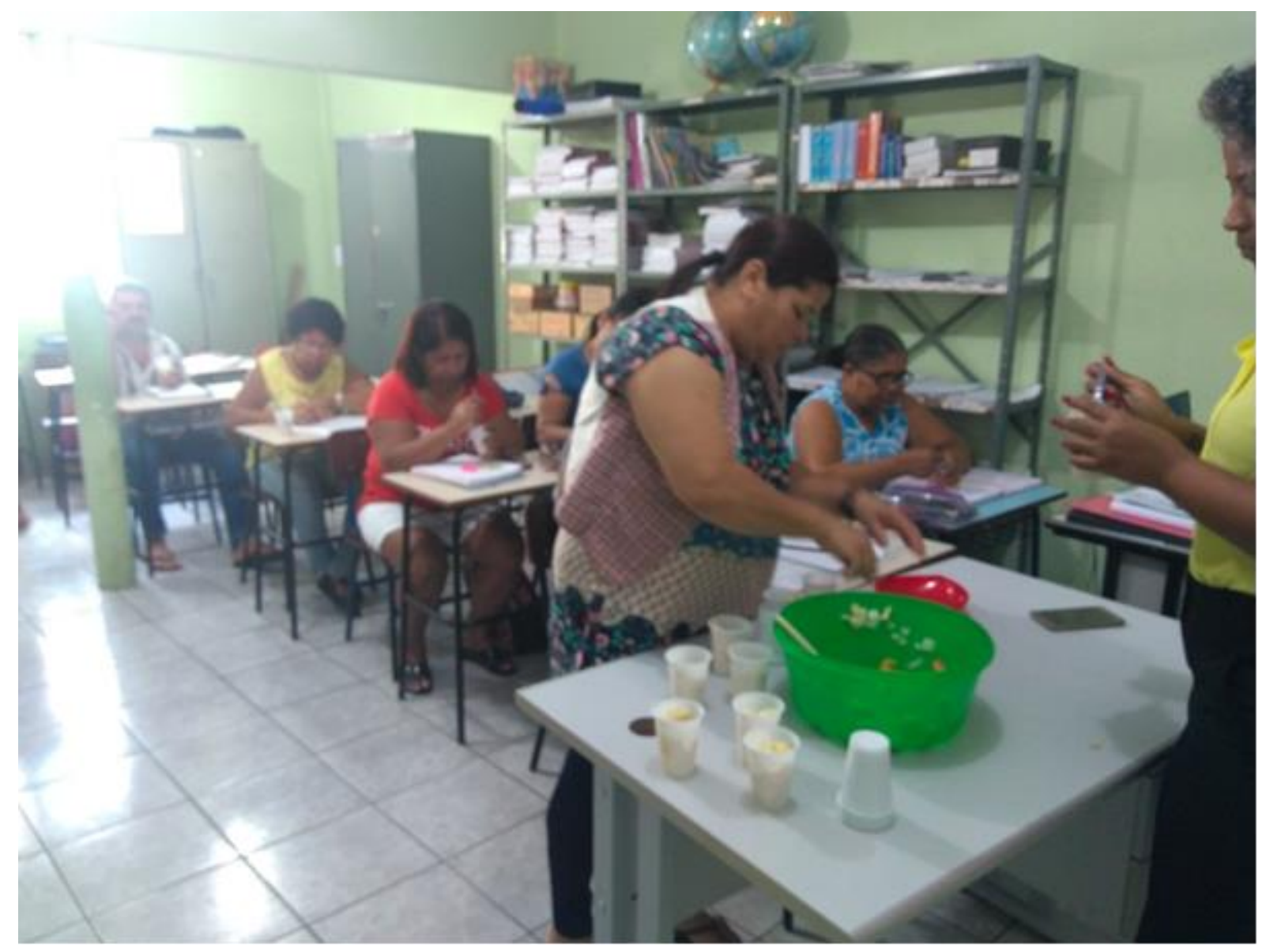

Da mesma forma que Brasil e Leite (2013) concluíram que a CTSA não deve ser uma abordagem somente das disciplinas da área da Natureza, a pesquisa nos levou a considerar a sua abordagem em outras disciplinas, de maneira interdisciplinar, cooperando entre as disciplinas para a construção do conhecimento científico, 
levando em consideração a cultura, sociedade que os alunos estão inseridos, unificando a visão do mundo.

Além disso, Dias, Leal e Júnior (2016) afirmam que a Educação Ambiental só é efetiva com a união da educação e da comunicação envolvida em um contexto interdisciplinar. De fato, a pesquisa desenvolvida proporcionou aos professores que abordam esse tema na escola pesquisada a reflexão sobre a prática ao conectar o contexto cultural e cotidiano do sujeito, propondo uma reflexão ampla para que os alunos possam ser mais solidários, críticos e proponham um ambiente mais socialmente justo e sustentável. Nesse sentido, vale ressaltar que em estudos desenvolvidos por Paulo Freire, nosso Patrono da Educação e um dos pioneiros professores da EJA, alfabetizou muitos trabalhadores dos setores urbanos e rurais com o intuito de melhorar seus afazeres em suas profissões, bem como ascensão a democracia das massas. Seu objetivo era "Uma educação para decisão, para a responsabilidade social e política." Freire possibilitou a libertação das classes populares, deu-lhes voz. (Paulo Freire, 1921-1997).

O ensino de Ciências é fundamental para a formação dos cidadãos, é importante que os professores abordem os temas em um contexto interdisciplinar a luz da abordagem CTSA, que integra ciência, tecnologia, sociedade e ambiente, para uma iniciação ou aprimoramento do conhecimento científico. Vivemos em um mundo rodeado de invenções tecnológicas, os impactos ambientais gerados por isso são incalculáveis, em contrapartida já não nos vemos sem energia, comunicação e outras tecnologias. O ensino de ciências tem o papel de auxiliar na formação de pessoas críticas, independentes, capazes de contribuir para a formação de um mundo ambientalmente sustentável, para isso os professores devem estimular a capacidade da resolução de problemas, indivíduos criativos, no entanto são 
necessários profissionais mais receptivos a informações e que possam reelaborar suas formas de lecionar, então se tornam imprescindível a formação contínua dos educadores (PARREIRA, 2012).

É muito raro encontrar alguém que não tenha, ou não teve contato com invenções científicas. Na Educação Ambiental os professores ainda separam o conteúdo do contexto social do aluno, o que limita o processo de ensino aprendizagem, impedindo assim que o indivíduo compreenda conhecimentos científicos que baseiam seu cotidiano, transmitindo então que Ciência é para um grupo seleto e que, somente algumas pessoas possuem esse conhecimento (MULINE; CAMPOS, 2013).

As Práticas pedagógicas que são aplicadas em Feiras de Ciências nas escolas públicas do ES contribuem para que a abordagem CTSA seja empregada de forma efetiva e funcional, permitindo melhoria dos conteúdos do contexto científico, permitindo criatividade, autonomia, protagonismo do aluno, auxiliando na formação de cidadãos mais críticos, engajados na sociedade, aliados a tecnologia e claro possibilitando a colaboração para um ambiente mais sustentável (BRASIL; LEITE, 2013).

Em uma pesquisa efetuada em outra escola pública do Estado do Espírito Santo, Oliveira, Pinheiro, Freitas e Menezes (2011) perceberam que ao realizar o trabalho de pesquisa, havia pouca articulação entre teoria e prática, além disso, encontraram falta de interesse e motivação pelos professores, o que acabou desmotivando os alunos em um primeiro contato, isso acontece muito nas escolas, às vezes um professor quer realizar um trabalho integrador com os estudantes e não encontra o apoio devido. Passadas os primeiros obstáculos, na realização do projeto 
notou-se interesse e curiosidade pelos alunos, o que contribuiu para uma transformação nas atitudes dos discentes em favor da sustentabilidade, sendo que o tema abordado foi às formas corretas do depósito de lixo, reutilização e reciclagem. É necessário que o professor rompa barreiras impostas pelo sistema, colegas, dele mesmo, diariamente, a fim de buscarmos uma educação de qualidade.

Atualmente com o avanço da ciência e da tecnologia, a Educação científica torna-se cada vez mais necessária, a tecnologia está presente em praticamente tudo, é dominada e adotada por todas as faixas etárias, principalmente pelos mais jovens. O avanço científico e tecnológico é uma preocupação social devido aos impactos gerados a ela e ao meio ambiente. É papel da escola, desenvolver nos alunos pensamentos críticos, não apenas na vertente que envolve a ciência, mas socialmente e ao meio ambiente. A introdução da linha CTSA proporciona a promoção do interesse pelo estudo da Ciência, permite uma visão mais crítica, envolvendo o aluno nas questões de ordem política, econômica, social, ambiental, permitindo melhor interação entre elas (MARCONDES et. al.,2009).

É função da escola possibilitar o desenvolvimento do pensamento crítico nos alunos, promovendo interesse pela Ciência, melhor compreensão das tecnologias, engajados pelos problemas sociais, ambientais, econômicos a fim de solucionar esses problemas (MARCONDES et. al., 2009). A alfabetização científica na Educação Básica através do ensino de Ciências tem importância ao transformar-se em um meio dos estudantes ampliarem seus aprendizados e cultura. A alfabetização científica permite com seus ensinamentos que o aluno empregue importantes papéis sociais, o de entender a leitura de mundo e, compreender a relevância de se modificar o mundo, no sentido de torná-lo um lugar melhor para se viver (CHASSOT, 2014). 
A aquisição da independência política parte do princípio do entendimento do contexto social e da natureza, em que possui preservação aos limites do meio ambiente e dos impactos da ação antrópica, além de torna-se muito necessária para uma educação voltada à conservação dos recursos naturais, para que possamos assim, usufruir de uma sociedade ambientalmente sustentável (SILVA \& CAMPOS, 2017).

A CTSA vai muito além do ensino de Ciências no contexto disciplinar, busca desenvolver a função crítica envolvendo principalmente a problematização dos temas socioambientais e tecnológicos (SANTOS, 2007) e busca motivar e incentivar os alunos a posicionar-se sobre determinados assuntos envolvendo discussões acerca da sociedade, identificando as Ciências e tecnologias como ações antropológicas, contribuindo com a construção de opiniões, discussões sobre o assunto e produzindo conhecimento científico (SANTOS, OLIVEIRA \& CORDEIRO, 2011).

Quando abordamos o tema educação ambiental estamos educando para a cidadania, enquanto formadores de opinião devemos buscar por meio de práticas dialógicas que os alunos se tornem mais solidários e respeitem às diferenças. $O$ exercício da cidadania não implica somente nas decisões políticas, mas na conservação do meio ambiente, tolerância, justiça social. Devemos propor novas práticas educativas ligadas aos problemas ambientais (JACOBI, 2005).

É importante que os alunos tenham posturas sociais construtivas, contribuindo para uma sociedade socialmente justa e um ambiente saudável, a Educação ambiental deve influenciar o aluno a buscar valores que permitam uma coexistência harmoniosa com o meio ambiente, compreendendo que a natureza não possui 
fontes inesgotáveis de recursos naturais, e como tal, devemos utilizar essas fontes de maneira consciente e racional (EFFTING, 2007).

A Educação Ambiental deve ser mais crítica, transformadora e emancipatória, convocando a educação, atribuir à intercessão da construção social, permitindo uma transformação da realidade, formando escolas mais sustentáveis (MACHADO, 2014). A linha CTS - Ciência, Tecnologia e Sociedade, conhecida nos anos 80, promoveu mudanças importantes no ensino de Ciências Naturais, deu ênfase a discussões coletivas de assuntos relevantes a sociedade, analisou a abordagem dos conteúdos, bem como sua organização, identificando a necessidade da integração dos conteúdos abordados a um contexto interdisciplinar, um dos grandes desafios para a didática atualmente (BRASIL, 1998, p.20-21).

Para Nascimento, Martins e Benite (2015), a Educação de Jovens e Adultos -EJA faz parte da Educação Básica do Brasil e é oferecida a alunos que estão em distorção série/idade, ou que por algum motivo não concluiu seu ensino na idade adequada, esse direito é assegurado por lei. O ensino de Ciências ajuda o aluno entender o contexto em que vive e na formação de cidadãos mais analíticos. A abordagem CTSA permite o conhecimento da Ciência, Tecnologia como produções humanas, e acionar a criticidade dos alunos mediante esses temas, bem como suas interferências no ambiente e sociedade.

Nascimento (2013) afirma que não é possível abordar a Educação de Jovens e Adultos sem discutir sem reconhecer o professor como incentivador de seus alunos, com função de estimular e mediar à aprendizagem, comprometendo-se com sua aprendizagem, levando em consideração o saber-prévio do público-alvo da EJA e adequando o currículo ao cotidiano do estudante. É importante considerar o contexto social e cultural em que o aluno está inserido, trazendo os alunos para o 
espaço em que sejam sujeitos do seu pensar, favorecendo uma educação com trocas de conhecimentos.

Medeiros, Souza, Silva e Cabral (2016) perceberam que a Educação Ambiental na EJA deve ser proposta de forma que integre o conhecimento à prática, para provocar nos discentes, mudanças de ações e concepções. A escola é o ambiente mais promissor para engajar a sociedade para ser sustentável, para tanto é importante que as disciplinas trabalhem conjuntamente, desenvolvam projetos que envolvam todos enfatizando a relevância do assunto e conscientizando para a preservação e manutenção da vida na Terra, incentivar o pensamento crítico, para que possamos colaborar para um ambiente protegido, minimizando a situação da atualidade. Santos (2014) desenvolveu um projeto que uniu o saber popular de alunos da EJA, com o conhecimento e utilização do sabão de óleo caseiro, os estudantes contaram ainda com aulas de química e Educação Ambiental, para saber os componentes utilizados para fabricação, bem como sustentabilidade. Para a fabricação do sabão foi necessário que os alunos levassem de casa óleos e embalagens usadas. Muitos estudantes demostraram surpresa com o impacto que esses produtos causam na natureza, que não tinham cuidado ao descartar esses materiais, com o projeto foi possível formar um ponto de coleta de óleos usados na escola. Os sabões produzidos foram distribuídos na escola. O estudo permitiu a percepção e a modificação das atitudes dos alunos, enfatizando a necessidade da realização desses projetos, principalmente com os alunos da EJA, pelas dificuldades que esses alunos apresentam com relação à realidade cultural.

Rodrigues et al. (2016) frisam a importância da Educação CTSA como um instrumento para o ensino na EJA, principalmente na Ciência, afirmando que com isso os estudantes desenvolvem autonomia e compreensão dos conteúdos que o 

norteiam, relacionando sua prática diária a conhecimentos científicos. É preciso que as escolas insiram a Educação Ambiental entrelaçando a teoria com a prática, permitindo que os estudantes entendam os impactos ambientais gerados por ações antrópicas, principalmente no seu entorno, favorecendo mudanças de comportamentos e atitudes com relação ao meio ambiente. É necessário ainda abordar a EA na EJA, com a finalidade de proporcionar a formação de cidadãos críticos e engajados nas situações problemas envolvendo o meio ambiente (ANDRADE, FRANCELINO, CRISPIM, SOUSA e LIMA, 2016).

Para Kruger e Leite (2010), na Educação de Jovens e adultos devemos priorizar os conhecimentos prévios e o contexto diário que o aluno está inserido, o emprego de aulas diferenciadas de forma mais prática e multidisciplinar facilita sua aprendizagem, vale ressaltar que o público da EJA é, na maioria das vezes, marginalizado do ambiente escolar e da sociedade.

Gouveia e Silva (2015) completam ainda que a EJA conta com pessoas que possuem idades, culturas, sonhos e vidas muito diversificadas, isso torna difícil uma aula, contexto de aprendizagem, que contemple toda essa diferença, para uma educação de qualidade é preciso romper essa barreira, contando com disponibilidade de conhecimentos, principalmente os conhecimentos científicos, explicando para os estudantes todos os processos que ocorrem em seu meio e em seu interior, para que adquiram consciência das intercorrências humanas e sociais. Na EJA é importante a introdução do CTSA para aquisição de conhecimentos para que o aluno deixe de adquirir assuntos segmentados e possa apresentar uma educação crítica, para isso é necessária uma educação integradora e interdisciplinar para que o estudante tenha uma visão integral do mundo, objetivando a formação de cidadãos participativos, capazes de opinar, decidir e transformar a realidade da sociedade que está inserido. 
Por isso, é imprescindível a alfabetização científica na EJA, para proporcionar aos estudantes conhecimentos variados, científicos, tecnológico, social e ambiental, a fim de proporcionar um futuro melhor.

\section{CONSIDERAÇÕES FINAIS}

O conjunto de práticas pedagógicas aplicadas à EJA teve como objetivo de identificar e analisar essas práticas na Educação Ambiental com enfoque na abordagem CTSA, visa também auxiliar os professores que trabalham com a EJA, a abordarem a temática em suas escolas de maneira crítica e interdisciplinar.

Para que isso ocorra, a escola é o local mais indicado para a popularização dos conhecimentos científicos, assim a sociedade será composta de pessoas mais analíticas e com o compromisso de tornar nosso planeta mais sustentável, só através de uma Educação Ambiental efetiva conseguiremos alcançar esses objetivos, juntamente com as questões políticas, sociais e econômicas.

As atividades desenvolvidas com a abordagem CTSA foram importantes por possibilitar para os alunos um ambiente que permitiu a construção e desenvolvimento de conhecimentos, sobre a forma de fazer ciência por meio de pesquisas e problematizações que precisou de empenho, que os aproximou de uma percepção mais ampla e crítica para o conhecimento científico e das relações que ele estabelece com o desenvolvimento tecnológico, a sociedade e o meio ambiente.

\section{AGRADECIMENTOS}

Acima de tudo, agradeço a Deus, minha fortaleza, onde encontro forças para vencer as adversidades da vida.

Ao CEEJA de Linhares-ES por ter viabilizado tempo e espaço para realização do meu trabalho de pesquisa, além da colaboração dos demais professores da escola. 


\section{REFERÊNCIAS}

Rev. Elet. DECT, Vitória - Espírito Santo, v. 10, n. 1, p.148-172, setembro de 2020

ANDRADE, Sanduel Oliveira; FRANCELINO, Arthur Victor Medeiros; CRISPIM, Diêgo Lima; SOUSA, Eliana Pereira; LIMA, Adriana Gomes. Percepção ambiental do corpo docente e discente da modalidade EJA de uma escola estadual no município de Pombal-PB. Revista Verde de Agroecologia e Desenvolvimento Sustentável - ISSN 1981-8203 - (Pombal - PB) v. 11, n.1, p.01-09, mar., 2016.

BRASIL, Faustini, Elizabeth Detone; LEITE, Sidnei Quezada Meireles. Projetos Escolares e Feira de Ciências: Construção da I Feira Estadual de Ciências e Engenharia do Espírito Santo, série Guia Didático de Ciências - n¹0, 2013.

BRASIL, Ministério da Educação - MEC. Base Nacional Comum Curricular. Homologada em dezembro de 2018. Disponível em <http://basenacionalcomum.mec.gov.br/a-base> Acesso em 28 de março de 2019.

BRASIL. Lei de Diretrizes e Bases da Educação Nacional. Lei número 9394, 20 de dezembro de 1996.

BRASIL. Ministério da Educação - MEC, Secretaria de Educação Fundamental (SEF). Parâmetros curriculares nacionais: ciências naturais. Brasília: EC/SEF, 1998.

CHASSOT, Attico. Alfabetização científica: questões e desafios para a educação. 6. ed. Ijuí: Unijuí, 2014.

DIAS, Leonice Seolin; LEAL, Aantonio Cezar; JUNIOR Salvador Carpi. Educação Ambiental: conceitos, metodologias e práticas. 1.a Edição TUPÃ - SP ANAP, 2016.

EFFTING, Tânia Regina. Educação Ambiental nas Escolas Pública: Realidade e Desafios. Trabalho de conclusão de curso (Especialização Planejamento para o Desenvolvimento Sustentável) - Centro de Ciências Agrárias, Universidade Estadual do Oeste do Paraná, Marechal Cândido Rondon, 2007. 
FREIRE, PAULO (1921 - 1997): Novas Leituras. Movimento-Revista de Educação, Niterói, ano 4, n.7, p.01-09, jul./dez. 2017.

FREIRE, Paulo. Pedagogia da Autonomia. Saberes Necessários à Prática Educativa. São Paulo: Paz e Terra, 1999.

FREITAS, Andréia Cristina Santos; SANTOS, José Everaldo Oliveira; BARRETO, Luciano Vieira. Educação Ambiental no Ensino de Jovens e Adultos. Centro Científico Conhecer - ENCICLOPÉDIA BIOSFERA, Goiânia, vol.5, n.8, 2009.

GOUVEIA, Daniele da Silva Maia; SILVA, Alcina Maria Testa Braz. A importância da alfabetização científica multidimensional na formação educacional da EJA: uma análise a partir das expectativas dos alunos. X ENPEC Águas de Lindóia, SP - 24 a 27 de novembro de 2015.

JACOBI, Pedro Roberto. Educação Ambiental: o desafio da construção de um pensamento crítico, complexo e reflexivo. Educação e Pesquisa, São Paulo, v. 31, n. 2, p. 233-250, maio/ago. 2005.

KRUGER, Joelma Goldner; LEITE, Sidnei Quezada Meireles. O ensino de química no curso técnico integrado PROEJA em metalurgia e materiais (IFES campus Vitória): análise das percepções discentes. Ciências e Cognição: Revista interdisciplinar de estudos e cognição. Vol.15, n.1 de 2010.

MACHADO, Júlia Teixeira. Educação Ambiental: um estudo sobre a ambientalização do cotidiano escolar. Tese de doutorado em Educação-USP, Piracicaba, São Paulo, 2014.

MARCONDES, Maria Eunice Ribeiro; CARMO, Miriam. P.; STUART, Rita C.; SILVA, Erivanildo L.; SOUZA, Fábio L.; JÚNIOR, João B. Santos; AKAHOSHI, Luciane. H. Materiais Instrucionais numa Perspectiva CTSA: uma Análise de Unidades Didáticas 
Produzidas por Professores de Química em Formação Continuada. Revista Investigações em Ensino de Ciências - V14(2), pp. 281-298, 2009.

MEDEIROS, Monalisa Cristina Silva; SILVA, José Adailton Lima; SOUSA, Cristiane Aureliano; CABRAL, Laíse Nascimento. A Educação Ambiental no Ensino de Jovens e Adultos nas escolas públicas: dificuldades e desafios. Publicado em $30 \quad$ de

agosto de $2016 . \quad$ Disponível em:

<http://educacaopublica.cederj.edu.br/revista/artigos/a-educacao-ambiental-no-

nsino-de-jovens-e-adultos-nas-escolas-publicas-dificuldades-e-desafios>. Acesso em 28 de março de 2019.

MOURA, Dante Henrique. EJA: Formação Técnica Integrada ao Ensino Médio. Boletim 16, 2006.

MUENCHEN, Cristiane; DELIZOICOV, Demétrio. Os três momentos pedagógicos e o contexto de produção do livro "Física". Ciência \& Educação (Bauru) ,v. 20, n. 3, p. 617-638, 2014.

MULINE, Leonardo Salvalaio; CAMPOS, Carlos Roberto Pires. A Prática Pedagógica em Educação Ambiental de Professores das Séries Iniciais de uma Escola do Município da Serra-ES: Um Estudo Crítico-Reflexivo. Práticas Pedagógicas em Educação Ambiental, Série Guia Didático de Ciências, 2013.

NASCIMENTO, Sandra Mara. Educação de Jovens e Adultos EJA, na visão de Paulo Freire.2013, 43 f. Trabalho de Conclusão de Curso (Especialização) Universidade Tecnológica Federal do Paraná, Paranavaí, 2013.

NASCIMENTO, Viviane Soares; MARTINS, Marcos Pereira; BENITE, Anna M. Canavarro. Sobre a Constituição da Matéria: Intervenção Pedagógica na Educação de 
Jovens e Adultos. $X$ Encontro Nacional de Pesquisa em Educação em Ciências $-X$ ENPEC Águas de Lindóia, SP - 24 a 27 de novembro de 2015.

OLIVEIRA, Ingrid Santos.; PINHEIRO, Nara. Zamagno; FREITAS, Cláudia Avellar; MENEZES, Paulo Henrique Dias. Problemas Ambientais Locais: educabilidades possíveis a partir do enfoque CTSA; Universida- de Federal de Juiz de Fora - UFJF. Abrapec,2011.

PARREIRA, Sofia Alexandra Nunes. Perspectiva CTSA - ciência, tecnologia, sociedade e ambiente no Ensino de Ciências- Instituto Politécnico de Bragança Biblioteca Digital, abril, 2012.

RODRIGUES, Joyce de Jesus; ARAÚJO, Carolynne Bonfim; LACERDA, Nília Oliveira Santos; QUEIRÓS, Wellington Pereira.; PAULO, Yasmin Julia Alves de. A Educação CTSA e temas geradores na perspectiva Freireana: Uma pesquisa tipo "Estado da Arte", nos últimos dez anos. XVIII Encontro Nacional de Ensino de Química (XVIII ENEQ) Florianópolis, SC, Brasil, 2016

SANTOS, Paulo Gabriel Franco dos; OLIVEIRA, Ernandes Rocha; CORDEIRO, Maria Angela de Moraes. V Encontro Regional Sul de Ensino de Biologia (EREBIO-SUL) 2011. Disponível em <http://www.uel.br/ccb/biologiageral/eventos/erebio/comunicacoes/T175.pdf>. Acesso em 28 de março de 2019.

SANTOS, Rosana Hansel. Práticas sustentáveis aplicadas em turmas da Educação de Jovens e Adultos - EJA. Encontro de Debates sobre o Ensino de Química -34으르 Inovação no Ensino de Química: Metodologia, Interdisciplinaridade e Politécnica. online.unisc.br. 2014. 
SANTOS, Paulo Gabriel Franco; QUINATO, Gabriel Augusto Cação; OLIVEIRA Ernandes Rocha. Relações Ciência, Tecnologia, Sociedade e Ambiente (CTSA) em salas de aula de Educação de Jovens e Adultos(EJA): Representações e Cidadania. Nutes. UFRJ. 2011.

SANTOS, Wildson Luiz Pereira. Contextualização no Ensino de Ciências por meio de temas CTS em uma Perspectiva Crítica. Ciência \& Ensino, vol. 1, número especial, novembro de 2007.

SILVA, Marcelo Scabelo; CAMPOS, Carlos Roberto Pires. Atividades investigativas na formação de professores de ciências: uma aula de campo na Formação Barreiras de Marataízes, ES. Ciência e Educcação, Bauru, v. 23, n. 3, p. 775-793, 2017. 